\title{
Vascular malformations of central nervous system: A series from tertiary care hospital in South India
}

Sudhir Babu Karri, Megha S. Uppin, A. Rajesh ${ }^{1}$, K. Ashish ${ }^{1}$, Suchanda Bhattacharjee ${ }^{1}$, Y. Jyotsna Rani², B. P. Sahu ${ }^{1}$, M. Vijaya Saradhi ${ }^{1}$, A. K. Purohit ${ }^{1}$, Sundaram Challa

Departments of Pathology, ${ }^{1}$ Neurosurgery and ${ }^{2}$ Radiology and Imageology, Nizam's Institute of Medical Sciences, Hyderabad, Telangana, India

\section{ABSTRACT}

Aims and Objectives: To describe clinicopathological features of surgically resected vascular malformations (VMs) of central nervous system (CNS). Materials and Methods: Histologically diagnosed cases of VMs of CNS during April 2010-April 2014 were included. Demographic data, clinical and radiological features were obtained. Hematoxylin and eosin slides were reviewed along with Verhoeff-Van Gieson (VVG), Masson's trichrome, periodic acid-Schiff, and Perls' stains. Morphologically, cavernomas and arteriovenous malformations (AVMs) were distinguished on the basis of vessel wall features on VVG and intervening glial parenchyma. Results: Fifty cases were diagnosed as VMs of CNS with an age range of $14-62$ years. These included 36 cavernomas, 12 AVMs, 2 mixed capillary-cavernous angiomas. Most of the cavernoma patients (15/36) presented with seizures, whereas AVM patients (8/12) had a headache as the dominant symptom. Twenty-nine patients were reliably diagnosed on radiological features. Microscopic evidence of hemorrhage was seen in 24/36 cavernomas and 6/12 AVMs, as opposed to radiologic evidence of 10 and 4, respectively. Reactive gliosis was seen in 16 cavernomas. Conclusions: Histological features are important for classifying the VMs of CNS as there are no specific clinical and radiological features. Type of VM has a bearing on management, prognosis, and risk of hemorrhage.

Key words: Arteriovenous malformation, cavernoma, hemorrhage, seizures

\section{Introduction}

Vascular malformations (VMs) of the central nervous system (CNS) are seen increasingly in clinical practice, primarily because of advances in cross-sectional brain and spinal cord imaging. Commonly encountered lesion types include arteriovenous malformations (AVMs), cavernous malformations, venous malformations, and capillary telangiectasias. Patients can experience various symptoms and signs at presentation. The natural history of VMs depends on lesion type, location, size, and overall hemodynamics. The natural history for each lesion

\section{Address for correspondence:}

Dr. Megha S. Uppin, Department of Pathology,

Nizam's Institute of Medical Sciences, Punjagutta,

Hyderabad - 500 082, Telangana, India.

E-mail: megha_harke@yahoo.co.in

\begin{tabular}{|l|l|}
\hline \multicolumn{2}{|c|}{ Access this article online } \\
\hline Quick Response Code: & Website: \\
\hline & www.ruralneuropractice.com \\
\cline { 2 - 3 } & \\
\hline & \\
\hline
\end{tabular}

subtype is reviewed, with special consideration of the clinical features, particularly hemorrhage and correlated with the imageological findings. Previously, many authors described these VMs occurring in the CNS predominantly based on the size, location, and morphologic typ $\mathrm{e}^{[1]}$ giving particular importance to site affected and morphologic pattern of the malformation and grouped them under several proposed classifications. ${ }^{[2]}$ The most followed classification is that by McCormick. ${ }^{[3]}$ In this article, we have emphasized on pathologic features of the surgically resected VMs of CNS.

\section{Materials and Methods}

This was a retrospective study of all VMs of CNS diagnosed at Nizam's Institute of Medical Sciences from

This is an open access article distributed under the terms of the Creative Commons Attribution-NonCommercial-ShareAlike 3.0 License, which allows others to remix, tweak, and build upon the work non-commercially, as long as the author is credited and the new creations are licensed under the identical terms.

For reprints contact: reprints@medknow.com

How to cite this article: Karri SB, Uppin MS, Rajesh A, Ashish K, Bhattacharjee S, Rani YJ, et al. Vascular malformations of central nervous system: A series from tertiary care hospital in South India. J Neurosci Rural Pract 2016;7:262-8. 
April 2010 to April 2014. The study was approved by Institutional Ethics Committee.

The clinical details of each patient were collected from medical records. Basic demographic data were studied which included age, gender, clinical presentation, radiologic findings, and location of the VM.

\section{Histopathologic features}

The morphological details of all the types of VMs were noted. These included caliber and type of the vessel, characteristics of the vessel wall, and the presence of collagen, media, elastic lamina, and intraluminal thrombosis/organization. Changes in adjacent parenchyma were also noted, which included reactive gliosis, hemosiderin laden macrophages, fibrosis, and calcification.

Morphologically, cavernomas and AVMs were distinguished on the basis of vessel wall features and intervening glial parenchyma.

Collagenization and muscularization of vessel walls were identified using Masson's trichrome (MT) stain.

Hemorrhage in the adjacent parenchyma was confirmed with the help of Perl's stain, highlighting the hemosiderin-laden macrophages.

Verhoeff's-van Gieson (VVG) was used in identifying the elastic lamina and periodic acid Schiff (PAS) helped in highlighting the hyalinized vessel walls.

\section{Results}

A total of 50 cases of VMs of CNS were diagnosed during the study period. Based on the characteristic morphology, these malformations were classified into cavernomas (36), AVMs (12), and mixed cavernous-capillary angiomas (2).

\section{Cavernoma}

\section{Clinical presentation}

The presentation and symptoms varied according to site and type of the VM. We summarized the age/sex distribution and sites affected by all VMs in Tables 1 and 2 , respectively. We summarized the clinical features of both cavernomas and AVM in Table 3.

There were 24 males and 12 females with male predominance $(\mathrm{M}: \mathrm{F}=2: 1)$. The age ranged from 14 to 62 years with a median age of 33.3 years. The most common presenting symptom was seizures that was seen in 16 cases $(44.4 \%)$ followed by a headache in 11 (30.6\%). Neurological deficits were also noted in $11(30.6 \%)$, which included paraesthesias occurring in $6(16.7 \%)$, weakness
Table 1: Age and sex distribution of cavernoma and arteriovenous malformations

\begin{tabular}{lcc}
\hline $\begin{array}{l}\text { Type of VM of } \\
\text { CNS }(\boldsymbol{n})\end{array}$ & $\begin{array}{c}\text { Age range } \\
\text { (mean) years }\end{array}$ & Male:Female \\
\hline Cavernoma (36) & $14-62(33.3)$ & $2: 1(24: 12)$ \\
AVM (12) & $15-48(26.8)$ & $2: 1(8: 4)$ \\
Mixed cavernous- & $15-20(17.5)$ & $1: 1(1: 1)$ \\
capillary angioma (2) & & \\
\hline $\begin{array}{l}\text { AVM: Arteriovenous malformations, VM: Vascular malformations, CNS: Central } \\
\text { nervous system }\end{array}$ &
\end{tabular}

Table 2: Sites of cavernoma and arteriovenous malformations

\begin{tabular}{cc}
\hline Cavernoma, $\boldsymbol{n = 3 6 ( \% )}$ & AVM, $\boldsymbol{n = 1 2 ( \% )}$ \\
\hline Cerebrum, $24(66.66)$ & Cerebrum, 11 (91.66) \\
Temporal, $9(25)$ & Frontal, $5(41.66)$ \\
Frontal, $8(22.22)$ & Parietal, $4(33.33)$ \\
Parietal, $7(19.44)$ & Temporal, $2(16.66)$ \\
Spinal cord, $5(13.88)$ & Spinal cord, $1(8.33)$ \\
Dorsal/lumbar, $5(13.88)$ & Dorsal/lumbar, 1 \\
& $(8.33)$
\end{tabular}

Brain stem, 4 (11.11)

Pons, 3 (8.33)

Midbrain, 1 (2.77)

Cerebellum, 4 (11.11)

Cerebellar hemisphere, 2

(5.55)

Cerebellar peduncle, 1 (2.77)

Cerebellar vermis, 1 (2.77)

Operculum, 1 (2.77)

Atria, 1 (2.77)

Ventricle, 1 (2.77)

Parasella, 1 (2.77)

AVM: Arteriovenous malformations

Table 3: Clinical features of cavernoma and arteriovenous malformations

\begin{tabular}{lcc}
\hline Clinical features & Cavernoma, $\boldsymbol{n}=\mathbf{3 6}(\%)$ & AVM, $\boldsymbol{n = 1 2}(\%)$ \\
\hline Seizures & $16(44.4)$ & $4(33.3)$ \\
Headache & $11(30.6)$ & $8(66.6)$ \\
Paraesthesias & $6(16.7)$ & $3(25)$ \\
Weakness of limbs & $4(11.1)$ & $3(25)$ \\
Visual disturbances & $3(8.3)$ & $3(25)$ \\
Speech disturbances & $2(5.6)$ & $2(16.6)$ \\
\hline
\end{tabular}

of limbs in $4(11.1 \%)$, visual disturbances in $3(8.3 \%)$, and speech defects in 2 (5.6\%). Majority of cavernomas were located in cerebral hemispheres accounting for $66.7 \%$ followed by a spinal cord (13.9\%), brainstem $(11.1 \%)$, and cerebellum (11.1\%).

\section{Imageological findings}

In Table 4, we summarized the imageological findings of both cavernomas and AVM. Out of 36 cases of cavernomas, 20 cases $(55.6 \%)$ were diagnosed on the basis of magnetic resonance imaging (MRI) [Figures 1 and 2]. A definite diagnosis of cavernoma 
was given in $58.1 \%(18 / 31)$ of the cases on the basis of MRI. Radiologic evidence of hemorrhage was noted in 10 cases $(27.8 \%)$.

\section{Histological findings}

In Table 5, we summarized the histological features of all the VMs. The histologic features of cavernomas included

\begin{tabular}{|c|c|c|}
\hline Investigation & Cavernoma & AVM \\
\hline \multicolumn{3}{|l|}{ MRI } \\
\hline Available & $31 * / 36$ & $7^{\# / 12}$ \\
\hline Reliable (\%) & $18(58.1)$ & $4(57.1)$ \\
\hline \multicolumn{3}{|l|}{ CT } \\
\hline Available & $12^{*} / 36$ & $5^{\# / 12}$ \\
\hline Reliable (\%) & 4 (33.3) & $2(40)$ \\
\hline \multicolumn{3}{|l|}{ DSA } \\
\hline Available & $1 * / 36$ & $7 \# / 12$ \\
\hline Reliable (\%) & $0(0)$ & 7 (100) \\
\hline
\end{tabular}

*Seven cases of cavernoma underwent both MRI and CT. And one case of cavernoma underwent both MRI and DSA, "Three cases of AVM underwent both MRI and DSA, 4 cases underwent both CT and DSA, and 2 cases underwent all the 3 investigations (CT, DSA, MRI). AVM: Arteriovenous malformations, MRI: Magnetic resonance imaging, CT: Computed tomography, DSA: Digital subtraction angiography. Available-number of cases who underwent MRI/CT/ DSA. Reliable-number of cases reliably diagnosed by MRI/CT/DSA

Table 5: Histological features in the adjacent/ intervening parenchyma

\begin{tabular}{lccc}
\hline Histology & $\begin{array}{c}\text { Cavernoma, } \\
\boldsymbol{n}=\mathbf{3 6}(\%)\end{array}$ & $\begin{array}{c}\text { AVM, } \\
\boldsymbol{n}=\mathbf{1 2}(\%)\end{array}$ & $\begin{array}{c}\text { Mixed cavernous- } \\
\text { capillary angioma, } \boldsymbol{n = 2}\end{array}$ \\
\hline Hemorrhage & $24(66.7)$ & $6(50)$ & 2 \\
Reactive gliosis & $16(44.4)$ & $6(50)$ & 1 \\
Calcification & $9(25)$ & $1(8.3)$ & 0 \\
Thrombi & $9(25)$ & $2(16.7)$ & 2 \\
Organization & $5(13.9)$ & $1(8.3)$ & 2 \\
\hline
\end{tabular}

AVM: Arteriovenous malformations

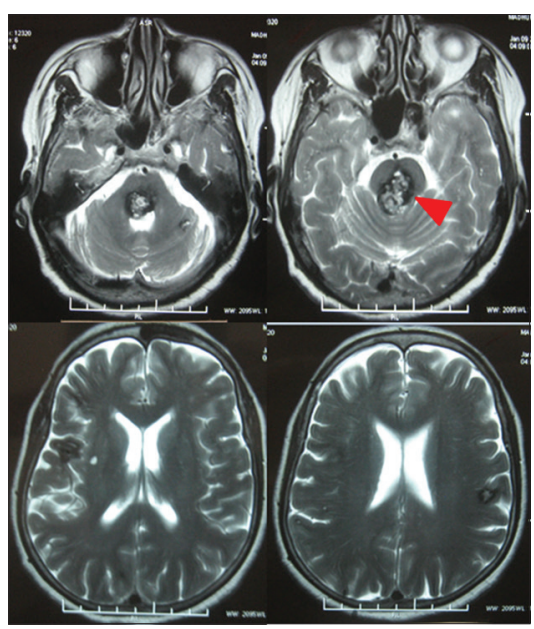

Figure 1: Case of multiple cavernoma: Axial T2-weighted images showing multiple focal altered signal intensities which are hyper intense with peripheral hypo intense rim due to hemosiderin rim in pons extending into pontomedullary junction, right frontal cortex and left parietal cortex. Lesion in pons is giving "popcorn" (red arrow head) appearance which is characteristic for cavernomas closely opposed hyalinized vessels/cystic vascular spaces lined by endothelial cells without any intervening neural parenchyma. The vessel walls were comprised of fibrous tissue without smooth muscle that was confirmed with the help of special stains such as MT and VVG [Figure 3].

Additional findings were seen adjacent to the main lesion. These included hemorrhage $(n=24,66.7 \%)$, reactive gliosis $(n=16,44.4 \%)$, and calcification $(n=9$, $25 \%)$. Intravascular thrombi were seen in 9 cases $(25 \%)$ of which 5 cases showed organization.

\section{Arteriovenous malformation}

There were 8 males and 4 females with male predominance $(\mathrm{M}: \mathrm{F}=2: 1)$. The age ranged from 15 to 48 years with a median age of 26.8 years. The most common presenting symptom was a headache $(n=8)$ followed by seizures $(n=4)$. Paraesthesias, weakness of limbs, visual disturbances were noted in 3 cases $(25 \%)$ each. Majority of AVMs were located in cerebrum accounting to $91.66 \%$ followed by spinal cord $(8.33 \%)$.

\section{Imageological findings}

The digital subtraction angiography (DSA) helped in making the diagnosis of AVM in $58.33 \%$ cases [Figure 4]. Radiologic evidence of hemorrhage was noted in 4 cases.

\section{Histological findings}

The characteristic features of AVM include hyalinized as well as muscularized thin and thick-walled vessels with intervening neural parenchyma [Figure 5].

Additional findings such a hemorrhage $(n=6)$, reactive gliosis $(n=6)$, calcification noted in a single case $(8.33 \%)$. Thrombi were seen in 2 cases $(16.66 \%)$.

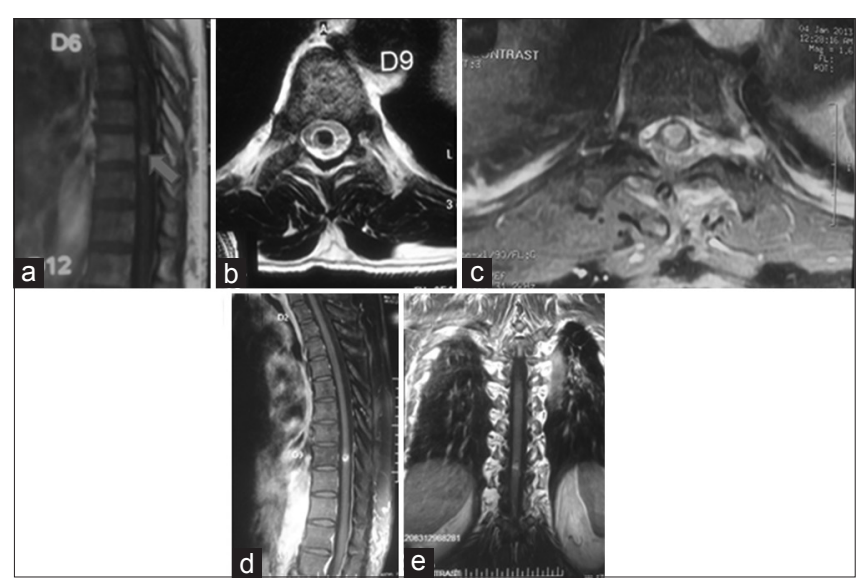

Figure 2: Case of spinal cavernoma: T1-weighted sagittal (a), T2-weighted axial (b) and postcontrast axial, sagittal, coronal (c-e) images respectively of dorsal spine showing small well defined focal altered signal intensity noted in the spinal cord at D9 vertebral body level which is hyperintense on T1-weighted (blue double arrow), hypointense on T2-weighted images showing no significant enhancement on postcontrast images suggests hemorrhage likely due to cavernoma 


\section{Mixed cavernous-capillary angioma}

There were 2 cases of mixed cavernous-capillary angiomas with one male (15 years old) and one female (20 years) patient.

A 15-year-old male patient presented with seizures and headache, and the 20-year-old female patient presented with neurological deficits (paraesthesias and weakness of limbs).

On microscopy, there were both cavernous and capillary sized vessels lined by endothelium and containing intraluminal red cells [Figure 6].

Both the cases showed microscopic evidence of hemorrhage with organized thrombi.

\section{Discussion}

McCormick ${ }^{[3]}$ classified intracranial VMs as arteriovenous, venous, cavernous, or capillary. This classification has been widely accepted by many. We have studied 50 cases of VMs of CNS. In our study, cavernomas were the most common VMs of CNS accounting for $72 \%$. Further, we have evaluated the clinicopathological features along with radiological correlation of all the VMs arising in the CNS. In both the cavernomas and AVMs, there was a male predominance with $\mathrm{M}: \mathrm{F}=2: 1$.

\section{Arteriovenous malformation}

A population study of Olmstead County identified 48 cases of intracranial VMs. ${ }^{[4]}$ Of these 48 cases, 26 (54\%) were AVMs, 14 (29\%) were venous malformations, $5(10 \%)$ were cavernomas, and $3(6 \%)$ were dural AVMs. In their study, all the AVMs were single and

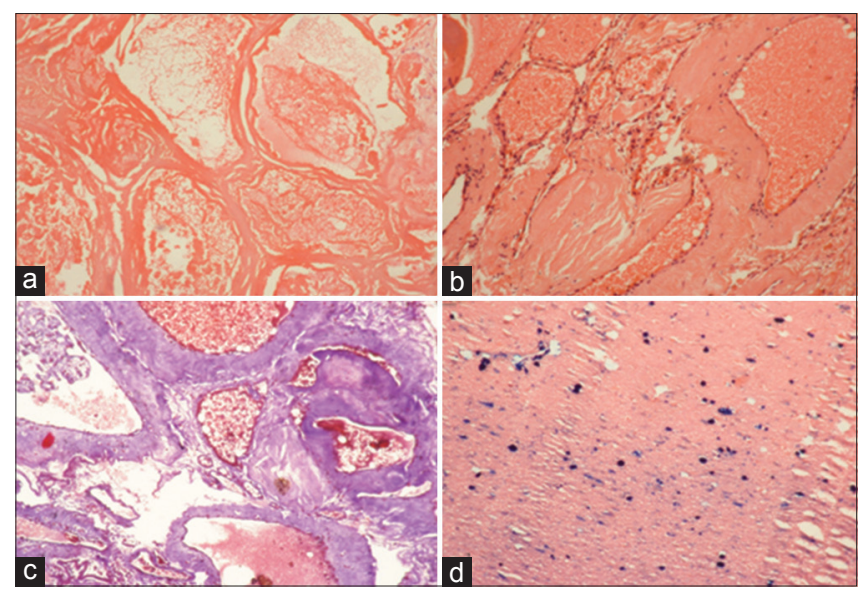

Figure 3: Histology of cavernoma: ( $a$ and b) Shows closely opposed congested vessels of varying sizes without any intervening neural parenchyma ( $\mathrm{H}$ and $\mathrm{E}, \times 100)$, (c) shows collagenized (fibrosed) vessel walls (MT, $\times 100$ ), (d) shows positive Prussian blue reaction in the adjacent neural parenchyma (Perl's, $\times 100$ ) sporadic, and genders were affected equally. Our observations were similar to their study but for male dominance.

Cerebral AVMs were the most common VMs with about 2500 new symptomatic cases presenting each year in the United States. ${ }^{[5]}$ In our study, we found that the cavernomas were more common than the AVMs, accounting for $72 \%(36 / 50)$ of all VMs, which may indicate selection bias of the hospital based data, but these VMs may show geographical distribution.

In our study, four cases (33.3\%) of AVM affected the children $\leq 18$ years of age. One case $(8.3 \%)$ of AVM showed recurrence.

In general, AVMs occur most commonly in cerebrum and one-tenth of all AVMs occur in the posterior fossa. ${ }^{[5]}$ In our study, we did not find any case of AVM occurring in the posterior fossa.

The sine qua non of an AVM is the angiographic demonstration of arteriovenous shunting. ${ }^{[4]}$ During the arterial phase of the angiogram, dye opacifies the nidus and the draining veins. In our study, all the patients (7/7) who underwent DSA were reliably diagnosed as AVM. Among the patients who underwent MRI, 4 cases $(80 \%)$ were diagnosed promptly except one, which affected the D1-D4 level of the spinal cord.

In AVMs, the characteristic histological features are vessels of varying sizes with intervening neural

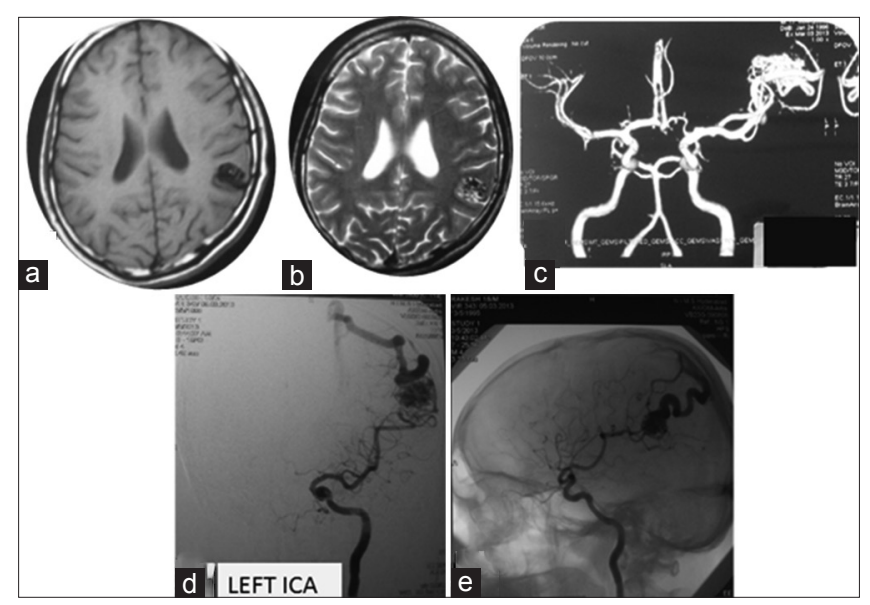

Figure 4: Case of arteriovenous malformation: ( $a$ and b) Axial T1-weighted and T2-weighted images showing focal altered intensity which is hypointense with hyperintensities on T1-weighted, hyperintense with hypointesne foci on T2-weighted in left parietal cortex, (c) magnetic resonance angiogram showing tangle of vessels from left middle cerebral artery. ( $d$ and e) Selective internal carotid artery vessel angiography showing a large arteriovenous malformation in left parietal region with feeders from middle cerebral artery branches and draining into superior sagittal sinus through hypertrophied cortical veins 
parenchyma. These vessel walls show varying thickness and show muscularization, which was confirmed with the help of special stains such as MT and VVG, where MT highlights the muscle tissue and VVG highlights the elastic lamina as well as muscle tissue in the vessel wall.

A prospective collection study of Hofmeister et al. showed the mean age at diagnosis of AVMs was 31 years. ${ }^{[6]}$ In their study, over half of the patients presented with hemorrhage, $40 \%$ with seizures, and $7 \%$ with persistent neurologic deficits, and $14 \%$ had a chronic headache. In our study, the mean age at diagnosis of AVMs was 26 years

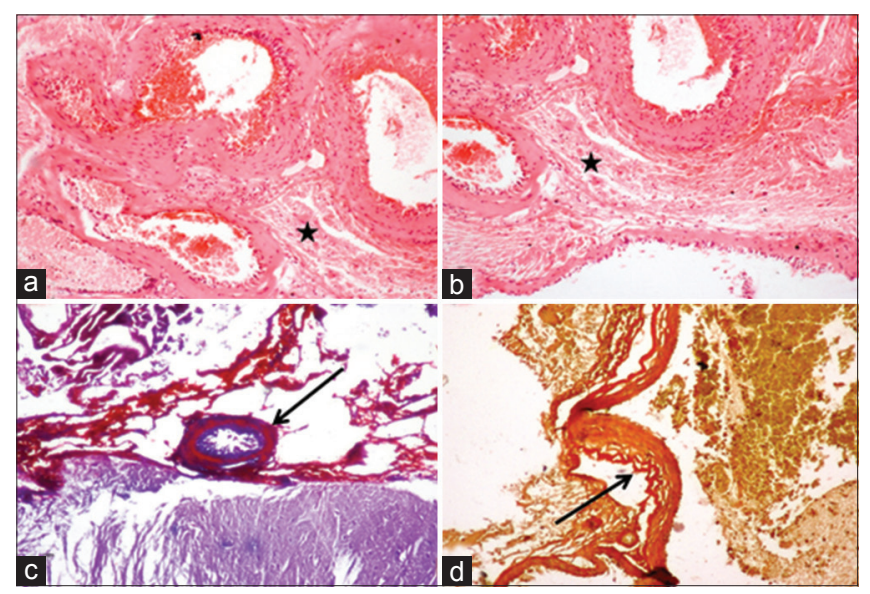

Figure 5: Histology of arteriovenous malformation: (a and b) Shows thick and thin walled vessels with intervening neural parenchyma (black stars) ( $H$ and $E, \times 100)$, (c) shows muscularization of the vessel wall (black arrow) (MT, $\times 100)$, (d) shows the internal elastic lamina (black arrow) (VVG, $\times 100)$ and $66.7 \%$ of the cases presented with neurological deficits (paraesthesias, visual, speech, weakness of limbs), $66.7 \%$ presented with a headache, $33.3 \%$ with seizures, $33.3 \%$ with hemorrhage (radiologically).

We compared our results of AVM with that of other studies [Table 6]. ${ }^{[6]}$ We found similar results with regard to radiologic evidence of hemorrhage. However, there are disparities regarding other features such as neurological deficits, headache, and seizures. This is probably because of the small sample size of the AVMs in our study.

\section{Cavernoma}

Cavernomas are at high risk for intraparenchymal bleed ${ }^{[4]}$ which can cause significant morbidity and mortality. Clinical practice focuses on identifying which unruptured CMs are most likely to bleed for the $1^{\text {st }}$ time after diagnosis.

Currently, CM location and past hemorrhage are used as predictors of the likelihood of future hemorrhage, and tend to be major determinants of whether CMs are treated. ${ }^{[4]}$

Cavernomas are usually seen in all parts of the CNS but are seen most often in the cerebrum. ${ }^{[7]}$ In our study also, they were found in all parts of the cerebrum, particularly, temporal lobe $(25 \%)$ and $13.6 \%$ of cases occurring in spinal cord. We also have cavernomas occurring at rare sites, one case $(2.8 \%)$ each in atria, parasellar region, and operculum.

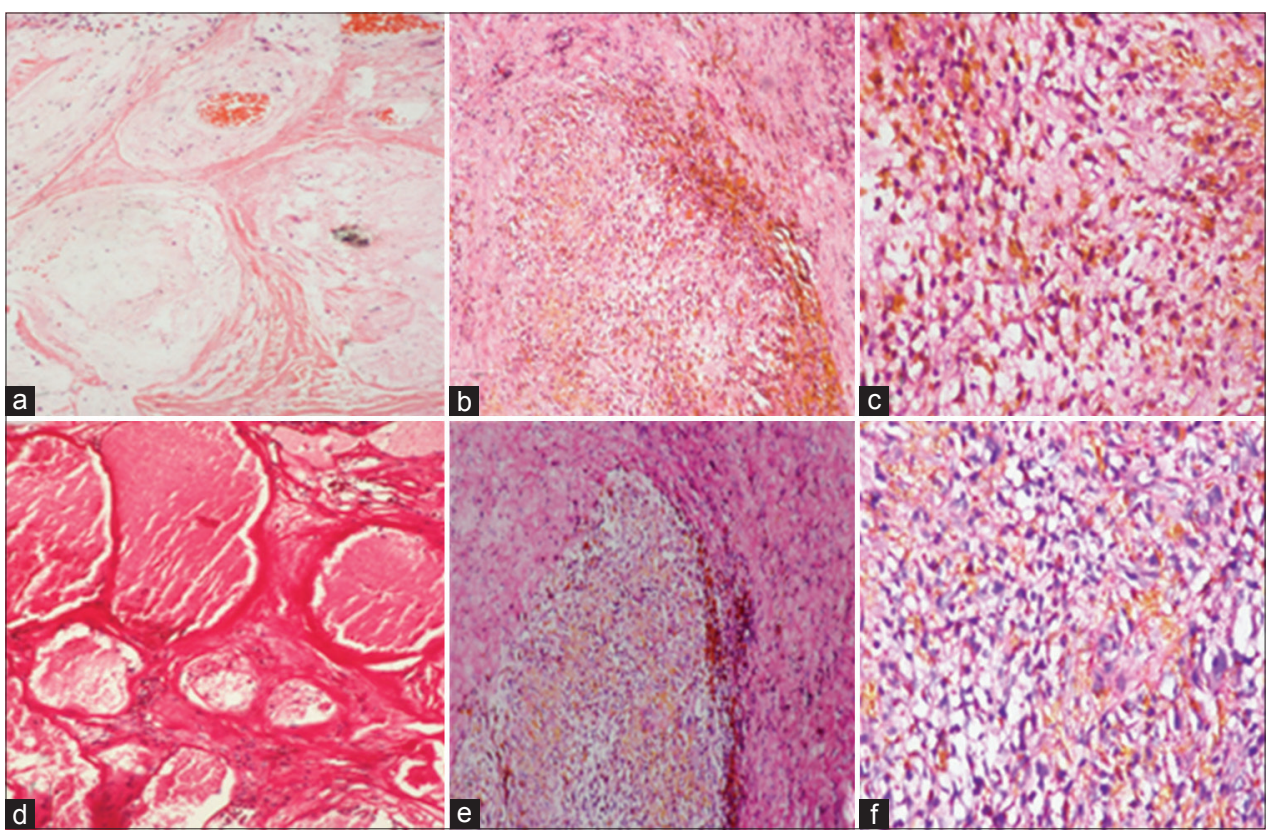

Figure 6: Histology of mixed cavernous and capillary angioma: (a) Shows cavernous angioma component with closely opposed fibrosed vessels, which are highlighted by PAS (d: PAS, $\times 100)$, without intervening neural parenchyma ( $\mathrm{H}$ and $E, \times 100)$, (b) low power view (H and $E, \times 40)$ of capillary angioma component with capillary-sized vessels, which are not highlighted by PAS (e: PAS, $\times 40)$, (c) medium power view (H and E, $\times 100)$ of capillary angioma component with capillary-sized vessels, which are not highlighted by PAS (f: PAS, $\times 100)$ 
Spinal cavernomas, generally are intramedullary and present with neurological deficits like paraparesis and sensory loss with stuttering, suggesting that the stepwise increases in cord dysfunction are related to repeated episodes of hemorrhage. ${ }^{[8]}$ In our study, we have $5 / 36$ cases $(13.6 \%)$ of cavernomas, which were intramedullary and presented with neurological deficits.

Multiple lesions are common in cavernomas. In a large 8131 MR scans, the incidence of cavernomas was $0.4 \%$, and the incidence of multiple lesions in this group was $18.7 \%{ }^{[7,9]}$ In the present study, we have $8.3 \%$ (3/36) of cases with cavernomas occurring at multiple sites.

Microscopically, all our cases of cavernoma showed characteristic features like vessels of varying sizes, which are closely opposed without any intervening neural parenchyma. And there is no muscularization of these vessel walls. This is the most important feature necessary to differentiate cavernomas from AVMs, which was confirmed with the help of special stains such as MT and VVG stain, where the MT came negative for muscle tissue and VVG did not highlight the elastic lamina/muscle tissue. The special stain, PAS helped in highlighting the collagenized/fibrosed vessel walls, which was helpful whenever the lesion was small, and showed vessels, which were thin walled and collapsed. In this way, special stains were helpful in differentiating the cavernomas from AVMs.

With the help of Perl's stain, we identified hemorrhage microscopically in more number of cases, $66.7 \%$ (24/36) of cavernomas, $50 \%(6 / 12)$ of AVMs [Table 5], which is in contrast to radiologic evidence of $27.7 \%$ (10/36) of cavernomas and $33.3 \%$ (4/12) of AVMs, respectively. Now, this difference was statistically significant. Whenever, hemorrhage occurs in the brain parenchyma, majority of the patients usually present with seizures, as iron is epileptogenic which is highlighted in our study with the Perl's stain. Seizures, if at all, occurred due to VMs, are generally refractory to medical therapy. Hence, in such type of conditions, appropriate surgical intervention is needed with proper diagnosis and classification.

Furthermore, in our study, majority of cavernomas presented with seizures, when compared to AVMs. Repeated hemorrhages from these cavernous malformations, a sine qua non of the disease, often without clinical manifestations, suggest that this is why they are the most common VM to cause seizures ${ }^{[4,10]}$ and why this is the most common clinical presentation.

The blood flow in cavernous angioma is slow ${ }^{[10,11]}$ and, therefore, stagnation of blood is characteristic and frequently the cause of thrombosis along with organization and calcifications too. ${ }^{[7]}$ In our study, we identified $25 \%$ (9/36) of cavernomas with calcification. Thrombosis was also noted in $25 \%$ of cases with organization of thrombi (cholesterol crystals) seen in $13.9 \%$ of all the cases of cavernomas.

Intracerebral hemorrhage in a patient younger than 40 without hypertension or coagulopathy has a high likelihood of being due to a VM, making angiography indicated in most cases. ${ }^{[4]}$

We compared our results with that of earlier studies and found to have similar results [Table 7].

\section{Mixed cavernous-capillary angiomas}

In a study conducted by Awad et al., out of 280 brain VMs, $14(5 \%)$ were mixed according to pathologic criteria and 11 contained cavernous malformation. Awad et al. also suggested that microhemorrhages around and within cavernous malformations might lead to reactive angiogenesis and formation of new

Table 6: Comparison of the results of arteriovenous malformations in this study with those of the previous studies

\begin{tabular}{|c|c|c|c|c|c|c|}
\hline & $\begin{array}{c}\text { Berlin, } \\
n=116(1997)\end{array}$ & $\begin{array}{c}\text { Paris, } \\
n=393(2000)\end{array}$ & $\begin{array}{c}\text { Middle and far } \\
\text { East, } n=91(2000)\end{array}$ & $\begin{array}{c}\text { New York, } \\
n=337 \text { (1997) }\end{array}$ & $\begin{array}{c}\text { Toronto, } \\
n=290(1998)\end{array}$ & $\begin{array}{c}\text { Our study, } \\
n=12(2014)\end{array}$ \\
\hline Hemorrhage (\%) & $49(42)$ & $212(54)$ & $87(57)$ & $148(49)$ & $173(60)$ & $4(33)$ \\
\hline Persistent neurologic deficit (\%) & $9(8)$ & $14(4)$ & $9(6)$ & $35(13)$ & NA & $8(66)$ \\
\hline Chronic headache (\%) & $21(19)$ & $57(16)$ & $18(13)$ & $28(10)$ & NA & $8(66)$ \\
\hline Focal seizure (\%) & $12(11)$ & $35(9)$ & $11(8)$ & $29(11)$ & NA & $4(33)$ \\
\hline
\end{tabular}

Table 7: Comparison of the results of cavernomas in the present study with those of the previous studies

\begin{tabular}{|c|c|c|c|c|c|c|}
\hline & $\begin{array}{c}\text { Giombini and } \\
\text { Morello, }{ }^{[2]} n=14(1978)\end{array}$ & $\begin{array}{c}\text { Simard et al., }{ }^{[12]} \\
n=126(1986)\end{array}$ & $\begin{array}{c}\text { Rigamonti et al.., }{ }^{[13]} \\
n=24 \text { (1988) }\end{array}$ & $\begin{array}{c}\text { Del Curling et al.., }{ }^{[9]} \\
n=36 \text { (1991) }\end{array}$ & $\begin{array}{c}\text { Robinson et al... }{ }^{[14]} \\
n=66 \text { (1991) }\end{array}$ & $\begin{array}{l}\text { Our study, } \\
n=36(2014)\end{array}$ \\
\hline Hemorrhage (\%) & 23.5 & 32 & 4 & NA & 10 & 27.7 \\
\hline Neurologic deficits (\%) & 12 & 29 & 15 & NA & 45 & 33.3 \\
\hline Headache (\%) & 28 & NA & 15 & 34 & 30 & 30.6 \\
\hline Seizures (\%) & 38 & 39 & 55 & 50 & 51 & 44.4 \\
\hline
\end{tabular}


vessels ("hemorrhagic angiogenic proliferation"). This process also has been suggested to lead to the growth of venous and capillary malformations and to mixed forms of malformations. ${ }^{[4]}$ In our study, out of $50 \mathrm{VMs}$ occurring in the CNS, $2(4 \%)$ were mixed and both the lesions showed cavernous malformation.

Histologically, these mixed cavernous-capillary angiomas show cavernous angioma component as well as capillary angioma component consisting of capillary-sized vessels.

\section{Conclusion}

Histological features are important for classifying the VMs of CNS as there are no specific clinical and radiological features. Type of $\mathrm{VM}$ has bearing on management, prognosis and risk of hemorrhage. The important principle of obtaining adequate tissue for histopathological diagnosis, even if the most advanced neuroradiology is employed, is emphasised. Intracerebral hemorrhage in a patient younger than 40 without hypertension or coagulopathy has a high likelihood of being due to a vascular malformation, making angiography indicated in most cases.

\section{Financial support and sponsorship}

Nil.

\section{Conflicts of interest}

There are no conflicts of interest.

\section{References}

1. Jellinger $\mathrm{K}$. Vascular malformations of the central nervous system: A morphological overview. Neurosurg Rev 1986;9:177-216.

2. Giombini S, Morello G. Cavernous angiomas of the brain. Account of fourteen personal cases and review of the literature. Acta Neurochir (Wien) 1978;40:61-82.

3. McCormick WF. The pathology of vascular ("arteriovenous") malformations. J Neurosurg 1966;24:807-16.

4. MacDonald RL, Stoodley M, Weir B. Vascular malformations of the central nervous system. Neurosurg Q 2001;11:231-47.

5. Peerless SJ, Hernesniemi JA, Drake CG. Arteriovenous malformations of the posterior fossa. In: Wilkins RH, Rengachary SS, editors. Neurosurgery. $2^{\text {nd }}$ ed. New York: McGraw Hill; 1996. p. 2463.

6. Hofmeister C, Stapf C, Hartmann A, Sciacca RR, Mansmann U, terBrugge $\mathrm{K}$, et al. Demographic, morphological, and clinical characteristics of 1289 patients with brain arteriovenous malformation. Stroke 2000;31:1307-10.

7. Rigamonti D, Hsu FP, Monsein LH. Cavernous malformations and related lesions. In: Wilkins RH, Rengachary SS, editors. Neurosurgery. $2^{\text {nd }}$ ed. New York: McGraw Hill; 1996. p. 2503-6.

8. Oldfield EH. Spinal vascular malformations. In: Wilkins RH, Rengachary SS, editors. Neurosurgery. $2^{\text {nd }}$ ed. New York: McGraw Hill; 1996. p. 2541-55.

9. Del Curling O Jr., Kelly DL Jr., Elster AD, Craven TE. An analysis of the natural history of cavernous angiomas. J Neurosurg 1991;75:702-8.

10. Forsting M, editor. Intracranial Vascular Malformations and Aneurysms: From Diagnostic Work-up to Endovascular Therapy. Softcover Edition. Germany: Springer; 2006.

11. Lowe LH, Marchant TC, Rivard DC, Scherbel AJ. Vascular malformations: Classification and terminology the radiologist needs to know. Semin Roentgenol 2012;47:106-17.

12. Simard JM, Garcia-Bengochea F, Ballinger WE Jr., Mickle JP, Quisling RG. Cavernous angioma: A review of 126 collected and 12 new clinical cases. Neurosurgery 1986;18:162-72.

13. Rigamonti D, Hadley MN, Drayer BP, Johnson PC, Hoenig-Rigamonti K, Knight JT, et al. Cerebral cavernous malformations. Incidence and familial occurrence. N Engl J Med 1988;319:343-7.

14. Robinson JR, Awad IA, Little JR. Natural history of the cavernous angioma. J Neurosurg 1991;75:709-14. 